\title{
FACTORS RELATED TO MYOCARDIAL INFARCTION AMONG YOUNG MALES IN CARDIOLOGY UNIT OF TEACHING HOSPITAL, KANDY, SRI LANKA
}

\author{
${ }^{1}$ Samarawickrama M. N., ${ }^{1}$ Tharangani R. K. N., ${ }^{1}$ Wijethilaka D.M.T.W., ${ }^{1}$ Nisanka G. M., ${ }^{1}$ Kumari L.Y.S.S. and \\ ${ }^{2}$ Siriwardana E.W.A.I.M. \\ ${ }^{1}$ Faculty of Health Sciences, The Open University of Sri Lanka, Sri Lanka \\ ${ }^{2}$ Department of Nursing, Sri Lanka Institute of Information Technology, Malabe, Sri Lanka
}

\begin{abstract}
Myocardial infarction (MI) is a major cause of death and disability worldwide. The purpose of this study is to examine the factors related to MI among young males (18-40 years) in Cardiology unit at Teaching hospital Kandy, Sri Lanka. The quantitative nonexperimental approach and descriptive correlational design was carried out to explore the factors related to MI among patients attending to cardiology clinic and wards in Teaching hospital Kandy. A researcher-administered questionnaire was distributed among 177 patients. Ethical approval was obtained from the same hospital. Data was analyzed by descriptive statistics using SPSS 22 version. Majority of the participants $(97.6 \%)$ were between aged 30 to 40. More than $90 \%$ of subject presented with dyslipidemia and high dietary intake of meat as physical risk factors. Under social factors, daily alcohol consumption and smoking reported in about $82 \%$ and $51 \%$ respectively while also $28 \%$ of participants engage in outdoor leisure time activities. Considerably less than $20 \%$ of respondents presented with anxiety and depression as the psychologically affected risk factors. Most of the risk factors which were found are modifiable factors like alcoholism, smoking and high dietary intake of meat. Therefore, it is recommended to have more awareness programs emphasizing the importance of adhering to life style modifications by means of reducing the risk and to control the further occurrence of MI of affected people.
\end{abstract}

Keywords - Myocardial infarction, alcoholism, smoking, life style modifications

\section{INTRODUCTION}

Myocardial infarction (MI) is usually known as the "heart attack" among the people. According to WHO (2017) reports, it is a major cause of death and disability worldwide. The worldwide incidence of Myocardial infarction has been increasing over the years and it has become the leading cause of death universally. Myocardial infarctions and strokes are responsible for 32.4 million deaths worldwide every year as mentioned by WHO (2018).

Mainly MI occurs in patients older than 45 years old. At present, the incidents reported with young men and women suffering from MI is considerably high according to Taber (2009). Further, the prevalence of MI among young male (1845 years) is very common than young female. Women typically suffer from heart disease ten years later than men as a result of the decrease in cardiac protective estrogen following the menopause (Nettina, 2009). However, when this disease condition occurs at young age usually it carries significant morbidity, psychological imbalances, and financial constraints for the diseased person and the family. The natural protection offered by the young age has been slowly taken away by the increased prevalence of risk factors for CHD in adolescents such as increase the rate of smoking, alcoholism and adherence to sedentary life styles.

MI can be defined as "the myocardial cell necrosis due to significant and sustained ischemia and also, usually, but not always, an acute manifestation of atherosclerosis-related coronary heart disease" (WHO, 2013). Several risk factors have been identified for MI among young males as dyslipidemia, smoking, and hypertension (Bhardwaj et al., 2014). MI among young males can be prevented by additional education on significant risk factors. However, it can be recognized by clinical features including Electro Cardio Graph and biochemical elevation. Common signs and symptoms are chest tightness, pain in the chest, arm and it spread to neck, jaw or back (Nettina, 2010). Fortunately, the prognosis is at a significant level when treated properly as they are young patients. On the other hand, poor control of risk factors carries a significant increasement of morbidity and mortality rates.

According to the profile of Sri Lankan, Bandara et al. (2005) reported that MI among the young males increase with smoking, hypercholesteremia, diabetic mellitus and hypertension. The literature review revealed there were less Sri-Lankan Studies regarding the factors related to Myocardial Infarction among young males. But numerous studies have been conducted globally. Therefore, Sri Lankan study on this 
topic is a necessity as MI among the young Sri Lankans is also increasing day by day as mentioned by Ministry of Health and Nutrition (2017). Furthermore, identification of risk factors will help to reduce MI among young males and indirectly it helps to reduce the cost of health utilization among them and it has a positive impact on the economy of the country.

The main purpose of this research is to study risk factors related to MI in young males in the Cardiology Unit in the Teaching Hospital, Kandy. Specific objectives are to identify the Physical factors, social factors and psychological factors related to MI among males (18-40 years) at cardiology unit in Teaching Hospital, Kandy. By doing this study we hope to emphasize the importance of secondary preventive measures in all young patients admitted with MI for preventing further attacks. Also, prevent MI among young males by disseminating facts through health education sessions.

\section{MethodOLOGY}

A quantitative non-experimental descriptive study was conducted in the cardiology unit in Teaching Hospital Kandy in Sri Lanka during 15th of January 2018 to 15th April 2018. A self-administered questionnaire was distributed among 177 patients, diagnosed with Myocardial Infarction, who were admitted in the cardiology unit, Teaching Hospital, Kandy on different domains such as physiological, social and psychological risk factors for MI among young males. The sampling was done by using convenient sampling method. Ethical approval was obtained from the Ethics Review Committee of Teaching hospital Kandy, Sri Lanka. The permission was obtained from the Director of the Teaching Hospital, Kandy. Data were analyzed by descriptive statistics using SPSS 22 version and summarized by frequencies and percentages.

\section{RESULTS}

Based on the collected data, expected to describe the demographic characteristics of the study participants, the physical factors, social factors and psychological factors related to MI among young males. Even though the sample size was 177 , the respondent rate was 170 .The proposed scheme is tested using ordinarily image processing. From the simulation of the experiment results, we can draw to the conclusion that this method is robust to many kinds of watermark images.
Table -1 Demographic Characteristics of the study participants

\begin{tabular}{|l|c|c|c|}
\hline $\begin{array}{l}\text { Demographic } \\
\text { characteristics } \\
\text { of the study } \\
\text { sample }\end{array}$ & Category & $\begin{array}{c}\text { Frequ } \\
\text { ency }\end{array}$ & $\begin{array}{c}\text { Percentage } \\
(\%)\end{array}$ \\
\hline Age (years) & $18-30$ & 0 & 0 \\
\cline { 2 - 4 } & $30-40$ & 166 & 97.6 \\
\cline { 2 - 4 } & $40-45$ & 4 & 2.4 \\
\hline \multirow{2}{*}{$\begin{array}{l}\text { Body Mass Index } \\
\left(\mathrm{kg} / \mathrm{m}^{2}\right)\end{array}$} & $<18.5$ & 6 & 3.52 \\
\cline { 2 - 4 } & $18.5-24.9$ & 47 & 27.6 \\
\cline { 2 - 4 } & $25-29.9$ & 113 & 66.4 \\
\cline { 2 - 4 } & $>30$ & 4 & 2.3 \\
\hline \multirow{3}{*}{ Ethnicity } & Sinhala & 136 & 80 \\
\cline { 2 - 4 } & Tamil & 10 & 5.9 \\
\cline { 2 - 4 } & Muslim & 24 & 14.1 \\
\hline Religion & Buddhist & 132 & 77.6 \\
\cline { 2 - 4 } & Hindu & 10 & 5.9 \\
\cline { 2 - 4 } & Islam & 22 & 12.9 \\
\hline
\end{tabular}

As interpreted in Table 1, 166(97.6\%) of study participants were aged between $30-40$ while only 4 belonged to $40-45$ age group. About two thirds of the respondents belonged to the overweight category $(\mathrm{BMI}=25-29.9 \mathrm{Kg} / \mathrm{m} 2)$ while around $27 \%$ had normal BMI and only around $2 \%$ were obese. In this study sample, 136 participants $(80 \%)$ were Sinhalese, $10(5.9 \%)$ were Tamils and $24(14.1 \%)$ were Muslims. Among them the majority were Buddhists and around 6\% and $13 \%$ were Hindus and Islamic respectively.

According to the research findings following data were met under physical risk factors of young males related to MI. Table 2 showed the family history of Non-Communicable Diseases (NCDs) and Figure 1 showed the pattern of the family history of NCDs.

Physical risk factors of young males related to MI

Table -2 Family history of risk factors

\begin{tabular}{|l|l|l|}
\hline Risk factor & Amount & Percentage (\%) \\
\hline Diabetes Mellitus (DM) & 76 & 45 \\
\hline Hypertension (HTN) & 66 & 39 \\
\hline Heart Diseases & 68 & 40 \\
\hline
\end{tabular}


Fig. 1. Pattern of family history of risk factors

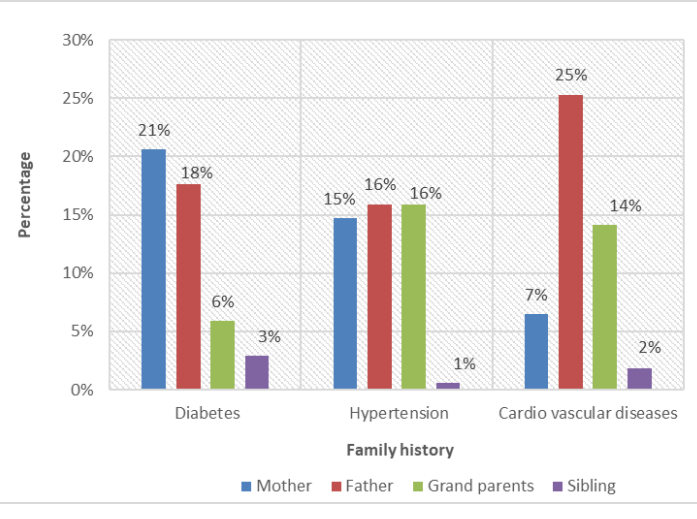

As per the present study findings, $40 \%$ of young males had family history of one or more NCDs. In here about $45 \%$ had the family history of DM. Among them, $21 \%$ of respondents had family history of DM from maternal paternity while $18 \%$ from paternal paternity. Further 39\% of respondents had the family history of HTN. Among them, $15 \%$ were reported with HTN from maternal paternity, $16 \%$ from their fraternal paternity while significantly another $16 \%$ from their grandparents. Furthermore, $40 \%$ of participants were reported with the family history of heart diseases. Among them, the majority were from paternal paternity while $7 \%$ were from their maternal paternity.

\begin{tabular}{|l|l|l|l|}
\hline $\begin{array}{l}\text { Physical } \\
\text { factor }\end{array}$ & Category Amount & $\begin{array}{l}\text { Percentage } \\
(\mathbf{\%})\end{array}$ \\
\hline $\begin{array}{l}\text { History of } \\
\text { risk factors }\end{array}$ & $\begin{array}{l}\text { Diabetes mellitus } \\
(\mathrm{DM})\end{array}$ & 26 & 15 \\
\cline { 2 - 4 } & Hyperlipidaemia & 156 & 92 \\
\cline { 2 - 4 } & Hypertension (HT) & 25 & 15 \\
\hline \multirow{2}{*}{$\begin{array}{l}\text { Treatment } \\
\text { pattern }\end{array}$} & $\begin{array}{l}\text { On regular } \\
\text { treatment }\end{array}$ & 141 & 83 \\
\cline { 2 - 4 } On got & $\begin{array}{l}\text { On } \\
\text { treatment }\end{array}$ & 7 & 12.4 \\
\cline { 2 - 4 } & $\begin{array}{l}\text { Stop treatment } \\
\text { Never }\end{array}$ & 4.1 \\
\hline
\end{tabular}

Table -3 The history of prevalence of risk factors of MI and pattern

Table 3 interpreted the history of the prevalence of risk factors of MI among young males in the study sample and pattern of treatment. Among 170 participants, 26 (15\%) had diabetes mellitus, 156 (92\%) of young males reported with hyperlipidemia and $25(18 \%)$ had hypertension beforehand diagnosed with MI. Also, 6 (4\%) of the study participants had none of the risk factors related to MI. Further, 11 respondents had both DM and Hyperlipidemia, 15 respondents had both Hyperlipidemia and HT and 13 respondents had both HT and
DM. Furthermore, 9 study participants of the study had all three risk factors. When considering the treatment patterns for the risk factors they were presented with; 141(83\%) of them were on regular treatments while only $21(12 \%)$ were on irregular treatments. Further, 7(4\%) of them stated that they had not taken treatment for any previously diagnosed risk factor.

Social factors related to MI among young males

\begin{tabular}{|l|l|l|l|}
\hline $\begin{array}{l}\text { Social } \\
\text { factor }\end{array}$ & Category & Amount & Percentage (\%) \\
\hline $\begin{array}{l}\text { Smoking } \\
\text { pattern }\end{array}$ & Non-smokers & 108 & 63.5 \\
\cline { 2 - 4 } & $\begin{array}{l}\text { Intermittent } \\
\text { smoking }\end{array}$ & 35 & 20.9 \\
\cline { 2 - 4 } & Daily smoking & 27 & 15.9 \\
\cline { 2 - 4 } & $\begin{array}{l}\text { Exposure to } \\
\text { passive smoking } \\
\text { (non-smokers) }\end{array}$ & 24 & 14.1 \\
\hline Alcoholism & Non-drinkers & 11 & 6.4 \\
\cline { 2 - 4 } & $\begin{array}{l}\text { Moderate } \\
\text { drinking }\end{array}$ & 49 & 28.8 \\
\cline { 2 - 4 } Habits & $\begin{array}{l}\text { Eat only home } \\
\text { prepared food }\end{array}$ & 65 & 31.3 \\
\cline { 2 - 4 } & $\begin{array}{l}\text { Usually eat fast } \\
\text { food \& food } \\
\text { from restaurants }\end{array}$ & 63 & 30 \\
\cline { 2 - 4 } & $\begin{array}{l}\text { Daily meat } \\
\text { consumers }\end{array}$ & 129 & 75.9 \\
\hline Light workers & 83 & 48.8 \\
\hline Physical & $\begin{array}{l}\text { Engage workers } \\
\text { outdoor leisure } \\
\text { time activities }\end{array}$ & 87 & 51 \\
\cline { 2 - 4 } & 48 & 28.2 \\
\hline
\end{tabular}

Table -4 Social Factors Associated with MI

As presented in Table 3, the study has tested the pattern of smoking, alcoholism, diet and physical activities as social risk factors related to MI among young males. Regarding the smoking pattern, more than half of the study subjects were non-smokers and about $14 \%$ were not exposed to passive smoking also. Moreover, $16 \%$ were heavy smokers and $31 \%$ were intermittent smokers. Among study subjects who belonged to the "non-smokers" category, 24 were exposed to passive smoking daily.

About two-thirds of the respondents were heavy alcoholics while 49 were moderate drinkers and only 11 were nondrinkers. When considering dietary habits of the study participants, about $31 \%$ of young males stated that they consume home-made food only while another $30 \%$ reported that they usually have food from restaurants and also consume fast food. Among them, there were 129 (75.9\%) daily meat consumers. Half of the study subjects were lightworkers and 
another half were reported as heavy workers. Among them, about $28 \%$ were engaged in outdoor activities.

\section{Psychological risk factors for MI among young males}

Table -5 Psychological Factors Associated with MI

\begin{tabular}{|l|l|l|}
\hline Psychological factors & Amount & Percentage (\%) \\
\hline Depression & 12 & 7 \\
\hline Anxiety & 8 & 4.7 \\
\hline Job related stress & 31 & 18.2 \\
\hline $\begin{array}{l}\text { Family life related } \\
\text { stress }\end{array}$ & 26 & 15.3 \\
\hline
\end{tabular}

As concluded in Table 5, 12 participants were diagnosed with depression while 8 were diagnosed with anxiety. Also 31 and 26 participants had stress which influenced by job and family problems respectively.

\section{DISCUSSION}

The majority (97.6\%) of study participants were aged between $30-40$. In contrast to the present study an Indian study was found that a smaller number of young adult males $(78.57 \%$ ) have belonged to the $30-40$ age categories. More than twothirds of the respondents belonged to the overweight category (BMI $>25 \mathrm{Kg} / \mathrm{m} 2$ ) while around $27.6 \%$ had normal $\mathrm{BMI}$ value $(\mathrm{BMI}=18.5-24.5 \mathrm{Kg} / \mathrm{m} 2)$. This result was incompatible with a study done in Southern Sri Lanka by Jayawardhana et al. (2017), as they found only $26.8 \%$ of the respondents have belonged to overweight category while about half of them were had normal BMI values.

\section{Physical risk factors for MI among young males}

Prevalence of family history among young males was accounted as $40 \%$. Among them altogether $39 \%$ were had the family history of HTN. This result was compatible with Akram et al (2015), as they found that the prevalence of the family history of coronary artery disease (CAD) is $36 \%$. However, Bhardwaj, Kandoria and Sharma (2014) noticed that family history of CAD was present in lesser amounts as $17.7 \%$.

Past history of having non-communicable diseases is a significant predictive factor of having MI in later life. Majority of the respondents (92\%) of the current study reported with hyperlipidemia while $15 \%$ had diabetes mellitus and $18 \%$ had hypertension beforehand diagnosed with MI. According to Katulanda et al. (2018) (A Sri Lankan study) revealed that $77.4 \%$ of Sri Lankan adults have some form of dyslipidemia. However, Bandara et al. (2017) identified in his study $39 \%$ of young male MI patients had increased LDL, as a percentage it was comparatively lower than what was found in the current study. Present study result was contrasted with a study done in India as $44.4 \%$ of respondents were reported with hypertension while only $8 \%$ were presented with diabetic mellitus beforehand diagnosed with MI (Bhardwaj, Kandoria and Sharma, 2014). Kiani, Hesabi and Arbabisarjou (2015) stated that in the same amount (26\%) participants had hypertension and diabetes history while about $15.5 \%$ were had cholesterol history. Finding regarding the prevalence of hyperlipidemia in the current study is compatible with a study done by Adam (2017) in Pakistan. But the other two risk factors were reported in high percentages as hypertension in $70.4 \%$ and diabetes in $51.2 \%$.

The percentages of presented with DM and HTN of a study conducted among the young Middle East and South Asian men by Jamil et al. (2013) were similar to current study results. But in contrast to the present study Zamani et al. (2017) revealed that 56\% had DM and 56\% had HTN.

\section{Social risk factors for MI among young males}

There are enough research findings to suggest that smoking may be the most prevalent risk factor among young MI patients. In the current study all together there were 62 smokers (37\%) while 24 nonsmokers were also exposure to passive smoking. A Sri Lankan study done by Kumarasiri et al. (2013) reported that smoking status has a significant association with MI. Akram et al (2015) and Bhardwaj, Kandoria and Sharma (2014) findings were little bit higher than current study findings. Those two studies were concluded that more than half of the participants were smokers as $56 \%$ and $58.8 \%$ respectively. Further, another two Indian studies conducted by Sinha (2017) and Bhandari et al. (2017) respectively were reported that more than two third of the participants did smoking. Also, contrast to the present study, Kiani, Hesabi and Arbabisarjou (2015) stated that only $13 \%$ of the respondents did smoking. Further, De Silva et al (2009) reported that the prevalence of smoking was $29.9 \%$ in urban areas and $24.4 \%$ in rural areas in Sri Lanka.

About half of the patients were heavy alcoholics and nearly $28 \%$ were moderate alcoholics in the current study. In comparison, another Sri Lankan study done by De Silva (2009) reported that the prevalence of alcohol use among males was $32.9 \%$. Similar to current study findings, Mostofsky et al. (2015) found that there were 55\% reported daily alcohol consumption in the US before the onset of MI compared with no alcohol consumption. Similar to present study Biyik et al. (2007) and Laatikainen et al. (2012) reported that heavy alcohol consumption promotes MI risk. In contrast, Darry et al. (2014) and Janszky et al. (2008) have reported that moderate alcohol consumption is associated with a decreased MI.

Significantly there were $75 \%$ of daily meat consumers and also $30 \%$ of the respondents were having fast foods from restaurants daily. According to a study done by Hunnicutt et al. (2014) at Indiana University reported with more than half of the participants were high meat consumers and it was a strong association between heme iron intake and MI.

In the current study half of the study participants were heavy workers while another half were light workers. Also, 28\% 


\section{International Journal of Engineering Applied Sciences and Technology, 2020 \\ Vol. 5, Issue 1, ISSN No. 2455-2143, Pages 478-484 \\ Published Online May 2020 in IJEAST (http://www.ijeast.com)}

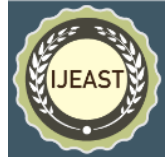

were engaged in outdoor leisure time activities. Akram et al. (2015) concluded that a higher prevalence of other factors of hypertension like obesity, sedentary life habits and feeding habits in the present study group could be a contributing factor for the high prevalence.

\section{Psychological risk factors for MI among young males}

In this study, there was a minimal association of psychological risk factors for MI among young males. Family life-related stress and work-related stress was around $15 \%$ among the subjects. Other psychological risk factors like anxiety and depression also presented less than $10 \%$. But in contrast to our findings most local and international study findings were revealed that psychological risk factors were closely associated with increased MI risk among young males (Kumarasiri et al., 2013, Xu T et al., 2011). In a Japanese study conducted by Yousefy and Nekouei (2013) identified depression, anxiety, and stress caused by life events as common psychological risk factors. It would be better to conduct further research on psychological risk factors as we were unable to identify a significant association of psychological risk factor for MI among young males. Studied conducted in Australia by Afzal et al. (2015) and Pakistan by Bunker et al. (2003) found that anxiety is an emerging risk factor for developing MI and also concluded, increased risk contributed by the psychosocial factors is similar order to the more conventional MI risk factors such as smoking, dyslipidemia, and hypertension.

\section{CONCLUSION}

The maximum number of patients was in 30-40 years of age. The youngest patient was 31 years old male. More than half of the young males were overweighed. Hyperlipidemia was the most commonly reported risk factor in the present study (92\%). Also, 18\% had hypertension and 15\% had diabetes mellitus. Considerably about half of the adult males were nonsmokers. But $14 \%$ of them were exposed to passive smoking. Moreover, $15 \%$ of the respondents did daily smoking. Further, half of the participants were heavy alcoholics as well as $29 \%$ of the respondents were moderate alcoholics. However, a significant percentage of substance abuse like heavy alcoholism and smoking were also able to identify as sociological risk factors. Two third of them were daily meat consumers. It was clear that there would be an association between these two factors as meat contains a high amount of fat. High meat consumers usually presented with dyslipidemia. There was a minimal association of psychological risk factors for MI among young males. Family life-related stress and work-related stress was around $15 \%$ among the subjects. Other psychological risk factors like anxiety and depression also presented less than $10 \%$.

In the current study the most common modifiable risk factor was hyperlipidemia and other common conventional modifiable risk factors in decreasing order of frequency were alcoholism, sedentary lifestyle, dietary patterns, smoking, hypertension, and diabetes mellitus.

Based on the findings we recommend conducting health community screening programs to identify the prevalence of risk factors of MI and to identify those who are vulnerable to develop risk factors. Further, recommended to conduct education programs for high-risk groups and programs aimed at preventing NCDs.

Shortage of similar studies carried in Sri Lanka and in other countries of the world especially on psychological risk factors makes the comparison and discussion difficult. The generalizability of the study finding was limited as the majority of the study participants were adult males (less than 40 years old).

\section{AKNOWLEDGEMENT}

We would like to express our deepest gratitude for all those who assisted and encouraged to conduct this study including research supervisors, study participants, and the director and the staff of the Teaching Hospital, Kandy. Also, our special thanks go to the Ethics Review Committee of the Teaching Hospital, Kandy Sri Lanka for giving ethical approval to conduct this study and Director and Chief Special Grade Nursing Officer in Teaching Hospital, Kandy in giving the permission to collect data. All the scholars whose article have been cited and included in the reference list of this paper are highly appreciated.

\section{REFERENCE}

1) Adam, A. M., Rehan, A., Waseem, N., Iqbal, U., Saleem, H., Ali, M. A., Shaikh, A. T., and Godil, A. (2017). Prevalence of Conventional Risk Factors and Evaluation of Baseline Indices among Young and Elderly Patients with Coronary Artery Disease. Journal of clinical and diagnostic research: JCDR, 11(7), (pp. 34-39). https://www.ncbi.nlm.nih.gov/pmc/articles/PMC5583 $772 /$

2) Afzal, S., Khan, M. A., Muhammad, H., Ashraf, A., and Afzal, M. (2015). Psychosocial risk factors of myocardial infarction and adverse effects of streptokinase in public sector hospitals. Pakistan journal of medical sciences, 31(4), (pp. 821-6). https://www.ncbi.nlm.nih.gov/pmc/articles/PMC4590 367/

3) Akram, M. V., Zaidi, F., Bansal, S., and Kishore, K. (2015). A study of risk factors in young patients of myocardial infarction. International Journal of Research in Medical Sciences. 3(10), (pp. 26772681). 


\section{International Journal of Engineering Applied Sciences and Technology, 2020 \\ Vol. 5, Issue 1, ISSN No. 2455-2143, Pages 478-484 \\ Published Online May 2020 in IJEAST (http://www.ijeast.com)}

https://www.msjonline.org/index.php/ijrms/article/vie w/1794.

4) Anand, S. S., Islam, S., Rosengren, A., Grazia, M., Krisela, F., Afzal, S., Yusufali, H., Keltai, M., Diaz, R., Rangarajan, S., and Yusuf, Y. (2008). Risk factors for myocardial infarction in women and men: insights from the interheart study. European Heart Journal, 29(7), (pp. 932-940). https://doi.org/10.1093/eurheartj/ehn018

5) Bandara, H. G. W. A. P. L., Kodithuwakku, N. W., Kogulan, T., Jegenathan, M. A. H., Siribaddana, D. M. J. M. H., Ambangamuwa, A., and Kularathna, S. A. M. (2016). Profile of Sri Lankan patients with myocardial infraction at younger age. Journal of the Postgraduate Institute of Medicine, 3. doi:10.4038/jpgim. 8105

6) Bhandari, M., Singh, V., and Venkatraman, D. (2017). A study of risk factors for acute myocardial infraction patients below 35 years in eastern India. Nigerian Journal of Cardiology, 14(2), (pp. 84-91). Doi:10.4103/njc.njc-10-17

7) Bhardwaj, R., Kandoria, A., and Sharma, R. (2014). Myocardial infarction in young adults-risk factors and pattern of coronary artery involvement. Nigerian medical journal: journal of the Nigeria Medical Association, 55(1), (pp. 44-7). https://www.ncbi.nlm.nih.gov/pmc/articles/PMC4071 $662 /$

8) Biyik, I., and Ergene, O. (2007). Alcohol and acute myocardial infraction. The Journal of International Medical Research, 35, (pp. 35-46).

9) Bunker, S. J., Colquhoun, D. M., Esler, M. D., Hickie, I. B., Hunt, D., Jelinek, V. M., Oldenburg, B. F., Peach, H. G., Ruth, D., Tennant, C. C., and Tonkin, A. M. (2011). https://www.ncbi.nlm.nih.gov/pubmed/12633484

10) Darry, P. L., Smyth, A., Teo, K. K., Kee, M. M., Rangarajan, S., Prem, P., Liu, L., Anand, S. S., \& Yusuf , S. (2014). Patterns of alcohol consumption and myocardial infraction risk, AHA Journals, 130(5).

https://www.ahajournals.org/doi/abs/10.1161/CIRCU LATIONAHA.113.007627

11) De Silva, R., Gamage, R., Wewelwala, C., Gunarathna, D., Kittner, S., Sirisena, D., Weerasinghe, A., and Amarasinghe, P. (2008). Young strokes in Sri Lanka: An unsolved problem. $\underline{J}$ Stroke Cerebrovasc Dis. 2009 Jul-Aug; 18(4), (pp. 304-308). $\underline{10.1016 / \mathrm{j} . j s t r o k e c e r e b r o v a s d i s .2008 .11 .004}$
12) Hunnicutt, J., He, K., and Hun, P. (2014). Dietary iron intake and body iron stores are associated with risk of coronary heart disease in a meta-analysis of prospective cohort studies. Journal of Nutrition, 144(3), (pp. 359). 10.3945/jn.113.185124

13) Jamil, M. G., Jamil, G., Alkhazraji, H., Haque, A., Chedid, F., Balasubramanium, M., Khairallah, and Qureshi, A. (2013). Risk factor assessment of young patients with acute myocardial infraction. American Journal of Cardio Vascular Disease, 3(3), (pp. 170174).

14) Janszky, I., Ljung, R., Ahnve, S., Hallqist, J., Bennet, A. M., Kenneth, J., and Mukamal. (2008). Alcohol and long term prognosis after a first acute myocardial infraction. European Heart Journal. 29(1), (pp. 4553). https://Doi.org/10.1093/eurheartj/ehm509

15) Jayawardene, J. B., Samarutilake, G. D. N., Zackie, M. H. M., De Silva, P. V., Karunanayake, A., and

16) Katulanda, P., Dissanayake, H. A., Silva, S. D. N., Katulanda, G. W., Liyanage, K., Constantine, G. R., Sheriff, R., and Matthews, D. R. (2018). Prevalence, patterns, and associations of dyslipidemia among Sri Lankan adults. Journal of Clinical Lipidology, 12(2), (pp. 447-454). 10.1016/j.jacl.2018.01.006 .https://www.ncbi.nlm.nih.gov/pubmed/29429894

17) Kiani, F., Hesabi, N., and Arbabisarjou, A. (2015). Assessment of Risk Factors in Patients with Myocardial Infarction. Global journal of health science, 8(1), (pp. 255-62). 10.5539/ gjhs. v8n1p255. https://www.ncbi.nlm.nih.gov/pmc/articles/PMC4804 079/

18) Kumarasiri, K., Mendis, M. R., Fernando, S. (2007). Risk factors for early MI. The Ceylon Medical Journal, 50, (pp. 51-54).

19) Laatikainen, T., Manninen, L., Poikolainen, K., and Vartiainenl, E. (2013). Increased mortality related to heavy alcohol intake pattern. Journal of Epidemiologiy and Community Health, 57(7). https://jech.bmj.com/content/57/5/379 2013.

20) Med J Aust. (2003, March). "Stress" and coronary heart disease: psychosocial risk factors. 17;178(6), (pp. 272-6).

21) Ministry of Health and Nutrition. (2017). Annual Health Bulletin 2015. Medical Statistics Unit of Ministry of Health and Nutrition, Sri Lanka. http://www.health.gov.lk/moh_final/english/public/el finder/files/publications/AHB/2017/AHB\%202015.p df 
22) Mostofsky, E., Vander Bone, J. G., Mukamal, K. J., Maclure, M., Tofler, G.H., Mullar, J., and Mitleman, A. (2015). Risk of myocardial infraction immediately after alcohol consumption. HHS Author Manuscripts, 26(2), 10.1097/EDE.000000000000022700000

(pp.143-150)

23) Nayak, P. R. and Yusuf, S. (2011). Risk factors for acute myocardial infarction in Indians: A casecontrol study. Lancet, 348, (pp. 358-363).

24) Nekouei, Z. K., Neshatdoost, H., Yousefy, A., Sadeghi, M., and Mansaee, G. (2013). Physiological factors and coronary heart disease. ARYA Atheroscler, 9(1), (pp. 102-111). https://www.ncbi.nlm.nih.gov/pmc/articles/PMC3653 $\underline{260 /}$

25) Nettina, Sandra, M. (2009). Lippincot Manual of Nursing Practice $\left(9^{\text {th }}\right.$ Ed. $)$. United States America.

26) Sinha, S. K., Krishna, V., Thakur, R., Kumar, A., Mishra, V., Jha, M. J., and Varma, C. M. (2017). Acute myocardial infarction in very young adults: A clinical presentation, risk factors, hospital outcome index, and their angiographic characteristics in North India. ARYA Atherosclerosis, 13(2), (pp. 79-87).

27) Southern Sri Lanka. (2017). Ceylon Medical Journal 2017, 62, (pp. 34-39).

28) Taber, P. (2009). Cardiovascular risk factors ( $2^{\text {nd }}$ Ed.). Williams and Wilkins, Philadelphia.

29) Weerasooriya, M. A. (2017). Prevalence of coronary artery disease in a semi urban population in

30) WHO, 2018, Prevention of Recurrences of Myocardial Infarction and Stroke Study?. https://www.who.int/cardiovascular_diseases/pri orities/secondary prevention/country/en/index1. $\underline{\mathrm{html}}$

31) World Health Organization. Hypertension and coronary heart disease: Classification and criteria.

32) Xu, T., Teo, K., Li, W., Wang, X. Y., Liu, L. S., and Yusuf, S. (2011). Association of psychological risk factors and acute myocardial infraction in China. Chinese Medical Journal, 124(14), (pp. 2083-8).

33) Zamani, B., Babapour, B., Amani, F., and Ghasemian, M. (2017). Comparing the risk factors of coronary artery diseases in patients with stenotic and ectatic lesions. International Journal of Community Medicine and Public Health, 4(12), (pp. 4411-4415). http://www.ijcmph.com/index.php/ijcmph/article /viewFile/2192/1622 